\title{
Reducing the Gap between Skills Sought by Employers and Developed by Education
}

Robert Peters, Western Michigan University

Melisa Beeson, Western Michigan University

ABSTRACT The process of transforming students from novices into experts relies on active learning and the development of an appreciation for the links among topics. Since rote or stimulus-response learning is preferred by a majority of students who are beginning their programs of study but does not optimize learning and understanding, the first step in the process is changing students' preference to active learning. As students progress from 100to 40o-level courses, this outcome can be accomplished by reducing the amount of class time that instructors dedicate to lectures that introduce new material and increasing the amount of time dedicated to active learning strategies. Because of PowerPoint's linear structure, teachers can foster learning by supplementing traditional slides with tables, charts, graphs, and concept maps that explicate the links among topics. Concept maps also lend themselves to assessing students' mastery of concepts and the value added by class discussions. Both measures enable instructors to enhance their teaching effectiveness and, over time, use class sessions more efficiently.

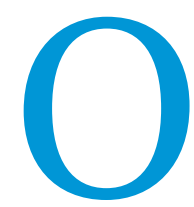

ne of the goals of a political science program is to transform novices into experts by developing a foundation on which students can build a structure for analyzing and understanding complex political processes. The achievement of this goal is partially dependent on the use of teaching strategies that are congruent with the students' preferred learning styles (Beck 2001; Fazarro et al. 2009). If, however, students' preferred learning styles do not maximize learning and understanding, then cultivating expertise also requires instructors to change the learning styles and adapt instructional strategies to the evolving learning styles. The process of cultivating expertise is also dependent on instructional strategies that assist students in developing knowledge structures that are readily amenable to expansion and revision.

Given the role of learning styles and instructional strategies in the development of experts, the first section of this article examines the preferred learning style with which most students enter higher education and contrasts this approach with one that max-

Robert Peters is an associate professor in the School of Public Affairs and Administration at Western Michigan University. He can be reached at robert.peters@wmich.edu. Melisa Beeson is an assistant professor in the School of Public Affairs and Administration at Western Michigan University. She can be reached at melisa.beeson@wmich.edu. imizes learning and understanding. The discussion is followed by an examination of teaching strategies that are appropriate for each learning style and that promote the evolution of learning styles. Since the use of PowerPoint presentations is pervasive in higher education, we also examine this approach's impact on the way in which students structure knowledge. The final section discusses the implications for political science instruction.

\section{LEARNING STYLES}

Rote learning, or stimulus-response learning, is the preferred learning style of most students who are beginning their undergraduate programs of study (Kinchin, Lygo-Baker, and Hay 2008). As is suggested by the terminology, this learning style emphasizes a process in which the instructor conveys and students passively consume the course materials. Since the accompanying assessment mechanisms focus on a prescribed set of readings, lecture notes, problem sets, and quizzes, students derive their responses from these sources to develop the "correct" responses, rather than searching their entire inventory of knowledge and problem-solving skills (Bernold 2005; Doyle 1988; Lithner 2008). Consequently, assessment mechanisms do not clearly indicate whether the students' responses are a measure of learning 
and understanding or are a reaction to the stimulus of exam questions (Billing 2007; Lithner 2008). In the latter instance, students can react to a question by replicating information memorized from the readings and class notes without necessarily understanding the material.

The findings from one of the authors' political economy courses illustrate the challenge of distinguishing between learning and understanding and responses to stimuli. In this course, the primary objectives, class discussions, and research paper requirements focused on identifying the cultural, economic, historical, and political factors that can constrain the range of viable policy options. Outcomes from each of the class discussions and research papers suggested that the students understood the relationship between the preceding factors and the probability of securing majority support for various policy options. However, this conclusion was undermined by the students' responses to an ungraded pre- and postcourse question that was administered in writing. Instead of including the traditional cues in the question (i.e., asking for the cultural, economic, historical, and political factors constraining the policy options), students were simply asked to of Bloom's taxonomy (Barkley, Cross, and Major 2005; Bruffee 1993), active learning promotes deeplearning (Reynolds 1994) that is associated with greater long-term retention, increased student motivation to pursue lifelong learning, and the development of analytical and thinking skills (McKeachie 1986).

Given the benefits of active learning, one of the challenges confronting undergraduate programs is transitioning students from their preference for stimulus-response learning to the adoption of active learning formats. A strategy for achieving this outcome is provided by examining student responses to one of the authors' open-ended course evaluation questions. Students in several of this author's courses expressed a preference for lectures whenever new material was being presented. Taken in conjunction with the course structure, this response suggests that a viable strategy is to use brief lectures to present new material, followed by active learning strategies that enable students to examine the material in greater depth. This approach maximizes the efficiency of conveying new material, provides an opportunity for students to apply and develop a deeper understanding of the material, creates a bridge between the students' preferred learning style and

\section{The process of transforming novices into experts occurs whenever students begin to develop cross links between each of these strands of knowledge. Novices are prone to believe that because Democrats currently hold a majority of House and Senate seats and occupy the White House, the party can quickly move its agenda through the legislative process. However, as the novices develop cross links among the previous topics (chains and spokes), they begin to understand that their initial assumption is erroneous.}

describe the approach they would use to analyze and develop options for several policy issues. Only two of the 12 postcourse responses applied the framework used in the class sessions and their research papers. All of the remaining students provided preand postcourse responses that were virtually identical and reminiscent of replies that would have been supplied by individuals who had never enrolled in the course. These results indicate that, given sufficient cues, the students were able to replicate the process but did not understand the rationale for using this approach. For most of the students, the probability of using the process at a later date therefore is quite low.

Because of stimulus-response learning's emphasis on transmission and replication rather than learning and understanding, an increasing number of educators are implementing active learning strategies in their classrooms. Instead of placing students in the role of passive consumers of information, there is an expectation that students be actively engaged in the learning process. The active participation of students is achieved by (1) discussions that facilitate the articulation of ideas, development of responses, and evaluation of evidence (Davis 1993); (2) debates that develop critical thinking skills and challenge students' existing assumptions (Barkley, Cross, and Major 2005); (3) simulations and case studies that facilitate evaluation and application; (4) cooperative learning that encourages group members to work together to maximize learning (Smith 1996); and (5) collaborative learning that defines the instructor and students as partners in the search for knowledge (Barkley, Cross, and Major 2005). By focusing on the higher learning skills one that maximizes learning and understanding, and promotes learning by maximizing the probability of a match between instructional approaches and the students' learning styles.

\section{TRANSFORMING NOVICES INTO EXPERTS}

The combination of stimulus-response learning and active learning cannot, in and of itself, transform novices into experts. Novices store information in the form of chains and spokes that show the links among components of a major topic, but they do not develop cross links among components of several major topics (Hay, Kinchin, and Lygo-Baker 2008). For example, the legislative process, the system of checks and balances, the founders' rationales for inhibiting the concentration of power, and the procedures for selecting lawmakers and the president are stored in distinct, independent chains or sets of spokes. The process of transforming novices into experts occurs whenever students begin to develop cross links between each of these strands of knowledge. Novices are prone to believe that because Democrats currently hold a majority of House and Senate seats and occupy the White House, the party can quickly move its agenda through the legislative process. However, as the novices develop cross links among the previous topics (chains and spokes), they begin to understand that their initial assumption is erroneous; the legislative process is typically slow and deliberate, because the founders established a system of checks and balances to inhibit the concentration of power, and Democrats from one region of the country do not hold the same policy preferences as Democrats from other regions. The 
development of experts therefore involves illuminating the connections among the various chains and spokes.

\section{POWERPOINT'S ROLE IN DEVELOPING EXPERTS}

Since PowerPoint is a pervasive component of instruction, it could play a crucial role in the development of experts. Unfortunately, PowerPoint's default structure, which relies on titles and subtitles, communicates information in a linear fashion and therefore is instrumental in constructing chains and spokes but not the links among them. PowerPoint, in other words, expands the number of chains and spokes stored by novices but does not explicate the links among the chains and spokes. Because of this limitation, students' ability to understand complex material and analyze complex political environments is limited (Kinchin, Lygo-Baker, and Hay 2008). When PowerPoint's linear structure is combined with the common assumption that the subtitles or bullet points are exhaustive and of equal importance, the approach encourages linear thought processes that not only dull students' critical faculties, but also inhibit improvisation and exploration (Gabriel 2008).

The limitations imposed by PowerPoint's default structure can be minimized by the use of innovative and imaginative formats. An approach suggested by Gabriel (2008) that we have found to be extremely useful involves the use of tables, diagrams, and charts to structure thinking, make complexity understandable, develop a deeper understanding of the links among concepts, and economically convey large amounts of information. For example, the relationship between safe congressional districts and lawmakers' ideologies can be assessed by means of a table that includes margins of electoral victory and the ratings generated by interest groups. Such an analysis provides a point of departure for examining both the primary process (e.g., the characteristics of people who vote and people who win primary elections) and the challenges of promoting bipartisanship in the legislative process. These formulations provide glimpses into the complexities of the policymaking process, foundations for developing connections between chains of knowledge, and the means for facilitating exploration and discussion between experts and novices. The use of tables, diagrams, and charts therefore enables participants to develop critical thinking, lifelong learning, and communication skills (Gabriel 2008).

A second approach counteracts the assumption that bullet points are exhaustive. The elimination or replacement of a set of bullet points with a phrase or sentence increases the probability that students will be engaged in the educational process and discovery of information (Apperson, Laws, and Scepansky 2008; Quible 2002). Whenever we have used this approach in advanced courses, there has been an increase in the volume of studentgenerated questions, contributions, observations, and development of concepts that were not addressed in the assigned readings. For example, one of the slides relating to term limits contained the title "The impact of term limits on the power and influence of legislative leaders" but no subtitles or bullet points listing the effects discussed in the readings. By following this approach, the students not only addressed most of the variables discussed in the readings but also generated additional variables and examples. Because of the increase in participation and discovery, classes with less detailed slides often require two to three times the amount of time to cover a given volume of material than do classes in which more detailed PowerPoint presentations are used. The evidence therefore supports the idea that PowerPoint is most valued by students when it is "used as a stimulus for elaboration, explanation, and discussion" (Apperson, Laws, and Scepansky 2008, 153). This concept also supports Gabriel's (2008) observation that less-detailed slide presentations give the instructor more latitude to deviate from the lecture plan, improvise, and create an environment conducive to developing new lines of thinking.

When pursuing these variations from the lecture plan and reading materials, the links between chains of knowledge must be defined. Otherwise, experience indicates that students, especially novices, are prone to view the discussions as tangents and express a desire to stay on topic.

\section{ENHANCING POWERPOINT'S IMPACT WITH CONCEPT MAPS}

PowerPoint's role in developing links among chains of information can be enhanced by the addition of concept maps. The process of developing concept maps is similar to constructing a house. In both instances, the project is divided into major components. Home construction is separated into tasks such as framing, plumbing, electrical wiring, and heating and cooling installation, while concept maps are divided into subtopics. The initial foci of training and education are the subunits of each major category. Carpenters, electricians, and plumbers focus on knowledge that is specific to their trade, while those who teach undergraduate courses address the elements that comprise their courses. For example, national government courses discuss the structure of government, the functions of each branch, the system of checks and balances, and the legislative process. State government courses discuss a similar set of elements, while intergovernmental relations courses examine the interactions among governments.

As with the trades, an understanding of the interrelationships among components is essential for developing expertise. Just as electricians are not fully informed or competent until they understand the interrelationships among the electrical system and other components of the house, students cannot graduate from novices to experts until they develop an appreciation for the linkages among topics discussed across courses. For the preceding set of courses, experts need to develop a complex web of links between the branches of each level of government, constitutional law, public opinion, and elections. The addition of concept maps to PowerPoint presentations therefore advances the development of expertise by visually delineating the links among chains of information and reinforcing the connections developed through the previously suggested use of tables, graphs, and charts. As suggested by Kinchin and Cabot (2007), the additions to PowerPoint can overcome the constraints imposed by its linear development of material, and the instrument can thereby become an important mechanism for transforming novices into experts.

Concept maps serve two additional purposes that enrich the educational process. The quality of communication between faculty and students can be enhanced by a comparison of their concept maps. Since faculty have developed complex concept maps with numerous cross links, and students are in the process of developing more expansive and complex maps, the differences in complexity are prone to create an environment in which faculty and students are "talking past each other." If, in more specific terms, instructors assume that a concept and its links with other concepts are common knowledge, they may address material at a level that is beyond the students' level of comprehension. Under these circumstances, students are less likely to understand the material 
and be able to frame questions that produce clarity. Students may also contend that the instructor knows the material but cannot communicate it in a way that students can understand.

The probability of miscommunication can be minimized if faculty draw concept maps of the course material and compare them to ones developed by students. We found it instructive to draw a concept map depicting the interactions among the concepts addressed by the course and then view the map from the perspective of students who are being exposed to the information for the first time. When this exercise was conducted for a health care finance course, one of the authors was astounded by the complexity of the map and could readily understand the basis for students' difficulty in understanding the material.

This exercise also revealed that one of the mechanisms for enhancing communication and student comprehension and learning is to simplify the concept map the instructor uses to develop course materials. When the simplified map is used as the basis for the course, learning is facilitated. As students develop an understanding of the map's chains of information and the links among them, the instructor can add links to the map and gradually build a more complex map that grows with the students' level of exper- entering institutions of higher education prefer stimulus-response learning, evidence indicates that active learning achieves greater learning and deeper understanding. The maximization of learning and comprehension therefore is dependent on weaning students off stimulus-response learning. Student responses to one of the authors' open-ended course evaluation questions suggest that change can be achieved by limiting lectures to the transmission of new information and using active learning to build upon this foundation. However, the benefits of active learning strategies are muted by PowerPoint. Its linear structure promotes the construction of chains of information but does not develop links between the chains of knowledge. Since students' transformation into experts is dependent on their capacity to develop and understand these cross links, strategies for overcoming PowerPoint's structural limitations should be implemented. Three of the innovations discussed in this paper are (1) the use of tables, graphs, and charts; (2) minimization of the number of subtitles or bullet points included in the slides; and (3) the addition of concept maps. The first and third initiatives focus on deriving links among chains of information, while the second promotes exploration and discovery.

\section{The addition of concept maps to PowerPoint presentations therefore advances the development of expertise by visually delineating the links among chains of information and reinforcing the connections developed through the previously suggested use of tables, graphs, and charts. As suggested by Kinchin and Cabot (2007), the additions to PowerPoint can overcome the constraints imposed by its linear development of material, and the instrument can thereby become an important mechanism for transforming novices into experts.}

tise. By gradually adding complexity to the course's initial concept map, students are enlightened about the nature of the links among concepts and are supported in the dialogue that assists them in their journey from novice to expert (Kinchin, LygoBaker, and Hay 2008).

Concept maps are also a mechanism for assessing student mastery of material. When students complete their maps after reading the assigned materials but before discussing them in class, the maps reveal the concepts and links they have mastered, as well as misconceptions and items they do not comprehend (Hay 2007; Hay, Kinchin, and Lygo-Baker 2008). Over time, the information provides an indication of the amount of class time that is needed for a student to achieve mastery of the material. An analysis of the preclass discussion concept maps therefore enables instructors to use class time more efficiently and effectively.

If students are periodically required to supplement the initial map with their own revised map that is completed after the material is discussed in class, a comparison of the two sets of maps can provide a measure of the extent to which the class discussions have clarified material that students did not initially understand or that they misinterpreted. The differences are also an indicator of the value added by class sessions.

\section{SUMMARY AND IMPLICATIONS}

The process of transforming novices into experts is affected by learning and teaching styles. Even though a majority of students
Concept maps are also a mechanism for assessing student mastery of course materials and the instructor's teaching effectiveness. Analyses of student-generated concept maps identify information that has been misinterpreted or not understood and therefore needs to be addressed during the ensuing class session. If students submit one concept map before the material is discussed in class and another after the discussion has concluded, a comparison of concept maps can identify topics for which class attendance produced significant, minor, or no changes in the students' understanding of the material. Minor or no changes occur when students are able to independently understand basic information. In these instances, class time can be dedicated to a more in-depth analysis of the topics and an examination of their linkages to other topics, rather than a review of material addressed in the readings. If limited improvements in comprehension are the product of insufficient clarification of more challenging topics, then an analysis of teaching techniques, examples, explanations, and readings is warranted. Limited improvements may also result from significant differences between the complexity of student and instructor concept maps. In this instance, the evidence suggests that communication, learning, and understanding can be enhanced by simplifying the concept map the instructor uses to develop course materials.

Transforming novices into experts requires the use of active learning approaches as well as additions to PowerPoint presentations that encourage students to develop links among chains of 
knowledge. Although implementation of these changes requires time and resources, the requisite commitment pales in comparison to the amount of time that is required to measure the value added by class attendance. The rewards are improvements in teaching effectiveness and the gratitude of students who appreciate their instructor's efforts to "give them their money's worth."

\section{NOTE}

This article is a revised version of a paper presented at the 67th Annual National Conference of the Midwest Political Science Association on April 3, 2009.

\section{REFERENCES}

Apperson, Jennifer M., Eric L. Laws, and James A. Scepansky. 2008. "An Assessment of Student Preferences for PowerPoint Presentation Structure in Undergraduate Courses." Computers \& Education 50: 148-53.

Barkley, Elizabeth F., K. Patricia Cross, and Claire Howell Major. 2005. Collaborative Learning Techniques: A Handbook for College Faculty. San Francisco: Jossey-Bass.

Beck, Charles R. 2001. "Matching Teaching Strategies to Learning Style Preferences." Teacher Educator 37 (1): 1-15

Bernold, Leonhard E. 2005. "Paradigm Shift in Construction Education Is Vital for the Future of Our Profession." Journal of Construction Engineering and Management 131: 533-39.

Billing, David. 2007. "Teaching for Transfer of Core/Key Skills in Higher Education: Cognitive Skills." Higher Education 53: 483-516.

Bruffee, Kenneth A. 1993. Collaborative Learning: Higher Education, Interdependence, and the Authority of Knowledge. Baltimore: Johns Hopkins University Press.
Davis, Barbara Gross. 1993. Tools for Teaching. San Francisco: Jossey-Bass.

Doyle, Walter. 1988. "Work in Mathematics Classes: The Context of Students" Thinking during Instruction." Educational Psychologist 23: 167-80.

Fazarro, Dominick E., Tim Pannkuk, Dwayne Pavelock, and Darcy Hubbard. 2009 "The Effectiveness of Instructional Methods Based on Learning Style Preferences of Agricultural Students: A Research Tool for Continuous Improvement for Faculty in Career and Technical Education (CTE) Programs." Journal of Industrial Teacher Education 45 (3): 84-104.

Gabriel, Yiannis. 2008. "Against the Tyranny of PowerPoint: Technology-in-Use and Technology Abuse." Organization Studies 29: 255-76.

Hay, David B. 2007. "Using Concept Maps to Measure Deep, Surface and NonLearning Outcomes.” Studies in Higher Education 32: 39-57.

Hay, David, Ian Kinchin, and Simon Lygo-Baker. 2008. "Making Learning Visible: The Role of Concept Mapping in Higher Education." Studies in Higher Education 33: 295-311.

Kinchin, I. M., and L. B. Cabot. 2007. "Using Concept Mapping Principles in PowerPoint." European Journal of Dental Education 11: 194-99.

Kinchin, Ian M., Simon Lygo-Baker, and David B. Hay. 2008. "Universities as Centres of Non-Learning." Studies in Higher Education 33: 89-103.

Lithner, Johan. 2008. "A Research Framework for Creative and Imitative Reasoning." Educational Studies in Mathematics 67: 255-76.

McKeachie, Wilbert James. 1986. Teaching Tips: A Guidebook for the Beginning College Teacher. 8th ed. Lexington, MA: D. C. Heath.

Quible, Zane K. 2002. "Maximizing the Effectiveness of Electronic Presentations." Business Communication Quarterly 65: 82-85.

Reynolds, Michael. 1994. Groupwork in Education and Training: Ideas in Practice. London: Kogan Page.

Smith, Karl A. 1996. “Cooperative Learning: Making 'Group Work’ Work.” In New Directions for Teaching and Learning, No. 67: Using Active Learning in College Classes: A Range of Options for Faculty, ed. Tracey E. Sutherland and Charles C. Bonwell, 71-82. San Francisco: Jossey-Bass. 


\section{CAMBRIDGE}

\section{JULNALS}

\section{WORLD POLITICS}

A Quarterly Gournal of International Relations

Volume 62, Number 2 April 2010
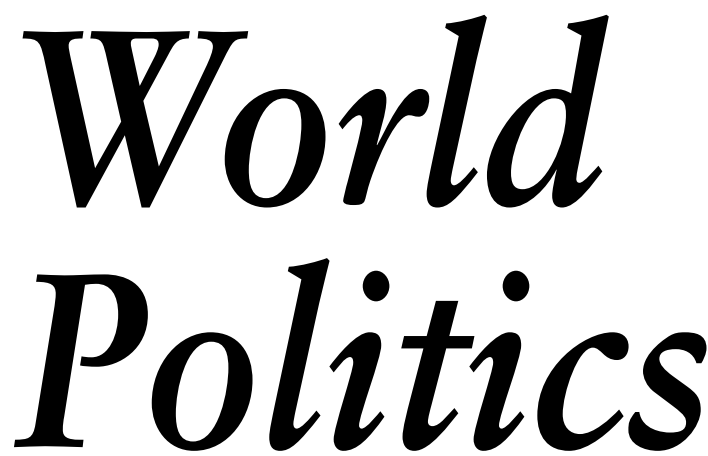

\section{Published for the Princeton Institute for International and Regional Affairs}

Editor: Atul Kohli, Princeton University, USA

World Politics, founded in 1948, is an internationally renowned quarterly journal of political science published in both print and online versions.

Open to contributions by scholars, World Politics invites submission of research articles that make theoretical and empirical contributions to the literature, review articles, and research notes bearing on problems in international relations and comparative politics. The journal does not publish articles on current affairs, policy pieces, or narratives of a journalistic nature. Articles submitted for consideration are unsolicited, except for review articles, which are usually commissioned.

Quarterly. Volume 62, 2010

ISSN 0043-8871. E-ISSN 1086-3338

$\square$ Students, Print Only: $\$ 31 / £ 17$

$\square$ Individuals, Print Only: \$36/£19

$\square$ Institutions, Print + Online: \$252/£139

$\square$ Institutions, Online Only: \$209 / £115

Name

Email

Address

$\square$ Check to Cambridge University Press in US \$ or $£$ Sterling

$\square$ Visa $\square$ MasterCard $\square$ American Express

Card number

Signature Expiry

\section{Subscribe!}

Recommend World Politics to your librarian directly from its homepage FREE online access for you when your library subscribes!

In the U.S., Canada, or Mexico, in US \$:

Journals Marketing Dept

Cambridge University Press

32 Avenue of the Americas

New York, NY 10013-2473, USA

Tel: $800-872-7423$ or $845-353-7500$

Fax: 845-353-4141

journals_subscriptions@cambridge.org
Elsewhere in the world, in $£$ Sterling: Cambridge University Press Journals Customer Services Dept Edinburgh Building Shaftesbury Road Cambridge CB2 8RU UK Tel: +44 (0) 1223326070 Fax: +44 (0) 1223325150 journals@cambridge.org

\section{journals.cambridge.org/wpo}

